The Geneva Papers on Risk and Insurance, 18 (No. 67, April 1993), 95-106

\title{
8th Geneva Lecture* Insurance Distribution Networks in Europe Current and Future Trends
}

\author{
by Michel Albert**
}

\section{Introduction}

Because of its rather atypical patterns of distribution, insurance may be considered a somewhat unorthodox activity. It embraces a wide range of different types of networks: from salaried intermediaries tied in very closely to the insurance companies themselves, and, in the case of many European countries, networks of general agents which, in spite of their independent status, act under a mandate as the representatives of insurance companies, through fully independent brokers.

This state of affairs is special, for, as a general rule, industrial or commercial undertakings having to deal simultaneously, and by no means always peaceably, with a range of entities as wide as this, are few in number. Yet, in professional realms closer to our own, this dichotomy is manifest. Deposit banks, for example, have within their structure fairly sophisticated networks of agencies and at the same time employ new entities specializing in financial management to market their products through the offices of independent advisors. This is particularly true of Great Britain following the adoption of the Financial Services Act.

The world of insurance is peculiar also in another respect: the more professional the product, the more it tends to be handled by independent networks. Elsewhere, indeed throughout industry and commerce, mass consumer goods are marketed by independent agents according to a traditional sequence: wholesaler, discount store and retailer, and more recently, supermarkets and megastores. By contrast, products of a more technologically innovative kind, aimed because of this at a smaller, more specialized clientele, are often distributed either through sales networks on the payroll of the firms manufacturing them, or by importers tied to the latter by commercial agreements. This applies, for example, to machine-tools and chemical products for trade use.

* Held in Brussels at the CGER, on March 31st, 1992, with the contribution of Mr. V. Croes, Administrateur Délégué, Groupe AG, Mr. M. Dewaersegger, Administrateur-Directeur, CGER, and Mr. J.-P. Gérard, Directeur Général-Administrateur Délégué, Royale Belge, Brussels.

** President, Assurances Générales de France (AGF), Paris. 
Moreover, within a single product range, thcre cxists, morc or less without cxception, a distinction between independent distribution at the bottom of the range and salaric distribution at the top. Computers are a case in point. Personal computers can today be purchased in most supermarkets and in a very wide range of retail establishments, while large computers designed exclusively for companies involved in highly complcx data-processing operations or working with very large computer files, are sold only by marketing engineers belonging to the firms manufacturing them. Highlighting and explaining the advantages of such products over those offered by competitors and negotiating discounts can only be adequately performed by persons with the rcquired cnginecring expertisc. This situation is typical of all scctors of the economy: from industrial fertilizers, "haute couture" and engineering goods to banking products.

Insurance is the only exception to this rule. The most ordinary kinds of policy, those designed for the general public, arc for the most part in practice marketed through salaricd networks for Life assurance and through tied networks, for example by general agents, for Non-Life insurance. Although in somc European countries, like Bclgium and Great Britain, broking is the pre-eminent channel for distributing personal policies, the very low unit commission for distribution means that in fact as a general rule a broker works with just four or five, frequently specialized, companies and thereby functions as a kind of part-time distributer for each of the companies concerned.

On the other hand, in high-risk areas, like Large Industrial Risk of Group Life Assurance for the staff of large undertakings, where complex issues of insurance technique need to be addressed, recourse to brokers or independent distributers is standard practicc because of the size of the premiums involved and because of the frequent need for coinsurance.

Let us now take a closer look at these two modes of distribution: the handling of large risk by brokers and of personal lines business by tied networks.

\section{Commercial risk and group life}

\subsection{The pre-eminence of broking in commercial risk}

In Europe, broking is the preferrcd mode for the marketing of insurance products to undertakings. Its share of the distribution of Non-Life policies issued to legal entities is $20 \%$ in Italy, $65 \%$ in Spain, $70 \%$ in Belgium and $85 \%$ in the Unitcd Kingdom, whilc for policies issued to largc undertakings alone this ratio lies within the much narrower range of from $85 \%$ to $95 \%$. Variations between countrics in fact reflect differences in cconomic structure: for small and medium undcrtakings the risks are fairly standard, similar to those in the personal risk category. It is thercforc only natural that tied networks should play an important part in the markcting of the policics designed to cover them. Italy being the European country whose prosperity is most dependent on the performance of small businesses, it should come as no surprise that it has the lowest ratc of distribution through broking. Great Britain, land of conglomerates, on the other hand, has the highest rate, especially since certain cultural factors - for cxample, the "maritimc" cconomic model" have tended to encourage this form of distribution.

\footnotetext{
1 Sce my book "Capitalisme contre capitalisme" - Editions du Scuil, September 1991.
} 
Moreover, not only in Europe but worldwide, broking has already entered a phase of restructuring which will probably continue to gather momentum. The take-over of the Dutch firm Hudig Langeveldt (14th largest worldwide) by the American firm Rollins Burdick Hunter (7th largest), of Coroon and Black by Willis Faber, of the French firm Faugère et Jutheau (15th largest) by world number one, the American firm Marsh and Mac Lennan, acquisition by the American Alexander and Alexander, world number two, of a majority share in the capital of the French SGCA, of a $27 \%$ holding in the French SIACI by the Jardine Group in Hong Kong (8th largest), a bid for a stake in the holdings of the French Gras-Savoye (17th largest) by one of its partners in the UNISON network (which includes the world's 5th largest broker, Johnson and Higgins)... The big American brokers are thus able to garner around $30 \%$ of their commission earnings in Europe.

These restructuring operations intensify broker specialisation in large risks. In this latter area, brokers are unique in being able - something which has been made possible in E. E.C. Member States by the FPS (Free Provision of Services) - to call upon companies which, in spite of their limited presence in the country of risk, have even so acquired in-depth experience of the latter. Brokers should in this way be able substantially to increase their share of the market in countries where, as is particularly the case in Spain, a sizeable proportion of commercial insurance is still handled by exclusive agents. Moreover, the increased concentration affecting a number of industrial activities upstream, with a consequent increase in the size of the global risks to be underwritten, should enhance this trend, it being in the interest of an undertaking seeking cover to have recourse to a broker able to take full advantage of international competition among companies.

Finally, competition among companies will in turn lead to a sharpening of competition among brokers and so speed-up the restructuring of the latter sector. That this is already occurring in Europe with some classes of large commercial risk would seem to suggest that brokers in countries virtually unaffected by the trend towards concentration occurring in the profession elsewhere will be particularly vulnerable.

In the case of France, one may assume that in the near future brokers will be faced with the prospect of growing outside competition from two different sources. First, from general agents whose exclusivity agreements will begin to be affected by European regulations (the resolution of 13 May 1991 adopted by BIPAR's European Commission). General agents will then be in a position to tackle new markets, especially under the pressure of competition from their own colleagues in other companies. Some general agents in France today are already starting to take on "the broker's mantel", as it were, for, in addition to their traditional business and with varying degrees of success, they are turning into part-time brokers in covering certain types of risk (especially SME risk).

A second source of competition brokers will have to face will be from undertakings themselves in their attempts to reduce the final cost of the insurance premiums they have to pay.

Alongside the self-broking or in-house departments that have existed for many years now, risk managers are beginning to appear in growing numbers in firms. In addition to their role of prevention and insurance optimization within the undertaking, increasingly the latter are acting as direct negotiators with insurance companies. Thus, a new kind of relationship between the undertaking and its insurer is emerging within which the broker's role 
is diminished. Clearly, consolidation of such trends on a large scale will not occur overnight, but in a world where cost compression has become, and is likely to remain, a number-one priority for both parties, it becomes increasingly obvious that the broker's monopoly of large risks cannot be guaranteed indefinitely.

\subsection{Broker professionalism and Europe}

There is clearly only one viable alternative open to brokers facing such trends: the service they offer to undertakings must become increasingly relevant and indispensable, in a word, more professional.

Indeed, with a fair number of undertakings which cannot afford, or do not wish, to employ a risk manager, it is in practice the broker who is called upon to perform this task. The latter's role of commercial intermediary is gradually giving way to that of advisor in respect of all insurance matters affecting the undertaking: Non-Life, Group Life, Operating loss, Sickness... The added value of the broker's technical expertise enables the undertaking to concentrate on substantive business rather than having to concern itself with insurance matters. It now has a representative mandated to defend its interests vis-à-vis insurers.

A broker, moreover, has an overall picture of the market which enhances his creativeness in transacting insurance business and enables him to be more reactive to the new insurance products companies devise in attempting to meet customer needs. This situation constitutes a genuine challenge for companies but also leads to a fair amount of duplicated, and even triplicated, effort: the more competent risk managers become and brokers with them, the more companies, if they are to keep up, must provide themselves with competent insurance technicians. And, at the end of the line, this also applies to reinsurers.

Finally, and perhaps most important of all, the creation of a close working-relationship with the client, an integral part of the broker's role as commercial intermediary, becomes crucial. The broker becomes, in effect, a representative, frequently viewed by the client as a trusted protector and advocate of the latter's interests when dealing with companies whose procedures and jargon appear at times impenetrable.

Developments on the European front are accelerating this transformation of the broker's traditional role by bringing into sharper focus its international and professional dimension. Increasingly, the bigger undertakings are acquiring a multiple presence in the European market and are beginning to feel the need for fully-fledged Europe-wide insurance programmes. In order to optimize the cost of insurance, an undertaking may well turn to a number of different companies for cover for its various establishments and types of risk. The ensuing, and now highly complex, operation of cover management needs to be placed in the hands of an expert: the broker.

The latter, above and beyond this basic service of admission of guarantees and coordination of policies programmes, must strengthen the local services and everyday assistance he provides to his client's European subsidiaries and establishments. Indeed, until such time as national legislation across Europe is made uniform, the risks to be covered and their management will continue to vary. Two examples of this are Group Life (where social liabilities depend on the public welfare system specific to each state) and Non-Life Insurance (where pollution-related risk is assessed differently according to whether the country in question is more developed and therefore, like Germany, more sensitive to the problem, or, like Portugal and Greece, less aware). 
One is tempted to extrapolate from current trends and to suggest that the next addition to the broker's remit will be the negociation of a single European insurance policy covering the entire range of risks the various establishments of an undertaking may be exposed to, especially medium-sized undertakings with a strong export orientation and a number of establishments across Europe. Even so, it should be remembered that the processes leading to the Europe of the future are hardly likely to be uniform ones and that, for example, social welfare systems are not exactly ideal candidates for harmonisation through Community regulation.

What these trends do mean, however, is that the broker's responsibility is destined to increase. In an FPS context, before selecting a foreign insurer, a broker will need to satisfy himself as to the latter's credit worthiness and promptness in settling claims, in short, as to the quality of the service he provides in exchange for the premium he charges.

Developments on the regulatory front will also be of crucial importance. European directives on the Free Provision of Services stipulate that, in respect of large risk (namely the range of risks faced by undertakings and hence also those with which the broker has to deal), the law of contract may be that of the country of the insurer. It will then be up to the broker to weigh the full implications of accepting a provision of this kind in the event of litigation following the filing of a claim. Thus, in the case of French law which is particularly favourable to the victim, a foreign insurer may be in a position to propose a lower premium should the policy stipulate that, wherever possible, disputes shall be subject to the jurisdiction of the insurer's country.

\subsection{Restructuring the broking market}

Today a broker can no longer afford to confine himself to underwriting large risks located within the borders of his own country. Internationalisation of industrial structures is bringing about an international concentration in broking which, in turn, is helping to strengthen the position of brokers as negotiators with insurance companies. That this is already occurring is clear from the one or two examples of regrouping referred to earlier. It is, in this regard, significant that in 1990 the world's four largest brokers handled $60 \%$ of the total business turn-over of the twenty largest broking firms worldwide, six, that is, out of a total of ten billion dollars (see Table below).

The European single market should promote and speed-up this process of concentration. International co-operative networks among brokers, like UNISON and International Broking Network, which enable their members to retain the management of the underwriting of risks located on their territory, are destined also to increase in number.

Just as the role of the broker is destined to evolve, so also, logically, must the manner of his remuneration change. A shift is already taking place away from the commission, the hitherto exclusive mode of payment which reflected the broker's traditional role as intermediary between the client and his market, to proper fees for insurance services rendered of the kind that an undertaking would normally expect to pay when in other fields it hires the services of an expert consultant.

Furthermore, the prevention and claims-management services a broker provides might well be remunerated in the form of a fee shared by the client undertaking and the insurance company. Indeed, in Australia shared fees of this kind already account for more than $60 \%$ of brokers' total turn-over. 
The 20 largest brokers: World ratings

\begin{tabular}{|l|c|c|c|c|}
\hline Groups & Nationality & $\begin{array}{r}\text { World } \\
\text { rating }\end{array}$ & $\begin{array}{r}\text { CA 1990 } \\
\text { (M } \$ \text { US })\end{array}$ & $\begin{array}{c}\text { Market } \\
\text { share }\end{array}$ \\
\hline Marsh \& McLennan & US & 1 & $2.756,5$ & $26,09 \%$ \\
Alexander \& Alexander & US & 2 & $1.353,8$ & $12,81 \%$ \\
Sedgwick & UK & 3 & $1.333,6$ & $12,62 \%$ \\
Willis Coroon & UK & 4 & $1.135,4$ & $10,75 \%$ \\
Johnson \& Higgins & US & 5 & 833,1 & $7,88 \%$ \\
Frank B. Hail & US & 6 & 443,1 & $4,19 \%$ \\
Rollins Burdick Hunter & US & 7 & 380,6 & $3,60 \%$ \\
Jardine & Hong-Kong & 8 & 324,5 & $3,07 \%$ \\
Minet & US & 9 & 318,0 & $3,01 \%$ \\
C. E. Heath & UK & 10 & 269,5 & $2,55 \%$ \\
Hogg & UK & 11 & 217,2 & $2,06 \%$ \\
Bain Clarkson & UK & 12 & 207,1 & $1,96 \%$ \\
Arthur J. Gallagner & US & 13 & 198,2 & $1,88 \%$ \\
Hudig-Langeveldt & NL & 14 & 136,3 & $1,29 \%$ \\
Faugère \& Jutheau & France & 15 & 129,0 & $1,22 \%$ \\
Jauch \& Hübner & FRG & 16 & 126,8 & $1,20 \%$ \\
Gras-Savoye & France & 17 & 125,2 & $1,18 \%$ \\
Hiib. Rogal \& Hamilton & US & 18 & 97,0 & $0,92 \%$ \\
Lowndes Lampert & UK & 19 & 92,2 & $0,87 \%$ \\
Sodarcan & Canada & 20 & 88,7 & $0,84 \%$ \\
Total for 20 largest & & & & \\
- & & & $10.565,7$ & $100,00 \%$ \\
\hline
\end{tabular}

Share of American brokers in first twenty

$60,39 \%$

Share of British brokers in first twenty

$30,81 \%$

Share of Continental European brokers in first twenty

$4,90 \%$

Source: Business Insurance dated July 1, 1991. 
The major development in broking over the next few years, however, may well prove to be the growth of in-house broking. This can be seen to occur in two different ways: the broking operations of the insurance companies themselves and broking activities undertaken by client firms, the latter being a natural extension of the functions of the risk manager in undertakings designed to reduce the net cost of insurance.

Currently there exist worldwide from three to five thousand in-house broking companies. In the USA more than one third of commercial Non-Life is handled by in-house brokers, while in Europe most of the large industrial groups have an in-house broking company at their disposal in Luxembourg.

In France, several insurers have either set up broking subsidiaries (AXA, GMF and Victoire for example) or have acquired a non-active holding - in order to avoid a clash of interests - in independent practices. The AGF and UAP, in association with other French companies, have in this way recently acquired a small stake in the Gras-Savoye practice in which the main shareholder is the American firm Johnson and Higgins.

Beyond to some extent influencing market access, in-house companies would not appear in economic terms to be particularly efficient: the prevailing ferocious competition on the commercial risks market has substantially depressed not only insurance rates but broking commissions as well, and, since in-house companies have structural costs of their own, the ultimate improvement in the net cost of insurance can therefore only be very marginal.

In spite of the changes the broking profession is bound to undergo, there will always be ample room in the insurance business for highly qualified intermediaries who are well organised and capable of providing an essential service to undertakings and companies alike.

\section{Personal fire, accident, liability and loss (IARD) risks}

\subsection{The situation varies enormously from country to country}

With Personal IARD cover, distribution is marked by enormous contrast as one moves from one country to the next across Europe. While in "maritime" countries, like Great Britain and Belgium, distribution through brokers is by far the predominant mode (from $80 \%$ to $95 \%$ of business depending upon the product), in the countries of Southern Europe as well as in France, Germany and other "alpine" countries distribution is handled by another kind of intermediary: the general agent. The share of personal Non-Life business handled through general agents is $40 \%$ in France, $60 \%$ in Germany and $80 \%$ in Italy.

In fact, the trend towards compression of insurance costs takes on different forms in different countries. In Great Britain and Belgium, brokers have set up powerful and extensive computerized information networks enabling them to select for their clients the lowest prices from a comprehensive menu of company rates. In France, on the other hand, another breed of actor, the MSI or Mutual Companies with direct sales forces, has come into the market fairly recently and has already acquired a sizeable share $(50 \%)$ of the motor insurance business. These mutual companies have managed to reduce the cost of insurance by simultaneously compressing the cost of distribution (using less intricate networks) and that of management (because of the way they are organised).

The secret behind the success of these MSI's has been their ability to "skim" the market, mainly by targeting a low or medium risk population (they, for example, frequently 
refuse to insure young drivers). They are then in a position to offer low rates, especially since the service they provide, in terms of its promptness and the level of indemnity offered, is by no means always equal to that of the more traditional companies.

The growth of these mutual companies now seems, however, to be levelling off. Having acquired the lion's share of the low-claim business, they can now only significantly increase their share of the motor-insurance market by expanding into higher-risk business, the more so because the traditional companies have reacted vigorously by refining their targeting and marketing techniques and are now frequently able to offer rates very close to those of the mutual companies.

\subsection{The rationale of increasing segmentation tends to undermine the very foundations of insurance}

It should first be made clear that market segmentation belongs properly to a "maritime" model of the economy. If we look back to the origins of insurance, we find, on the one hand, the first benefit societies set up by the villagers who inhabited the high alpine valleys, and, on the other, the venture loans raised in respect of ship-borne cargoes. These two foundations of insurance give rise to two clearly differentiated models. First, the "alpine" model whose chief characteristics is best exemplified by the existence of a single and compulsory rate for third-party motor insurance, reflecting as it does a high degree of riskpooling or even of solidarity and engendering stability of customership and, for insurance firms, financial power. Second, the "maritime" model whose spirit harkens back to the trading halls of former times and whose effect has been to "depool" risk through hypersegmentation, to destabilize customership and, even, to errode the financial soundness of insurance companies.

Where the "maritime" model prevails, insurance companies tend to segment the market into their own increasingly fine categories and the broker, in comparing the rates of a number of companies, as he must, is faced with a tariff range reflecting a gearing-down of the market and resulting at times in a situation which runs counter to the very principle of insurance. For would not indefinite segmentation of the market ultimately lead to a state of affairs where each client would be paying a tailor-made premium which exactly reflected the extent of his or her risk?

In the United Kingdom, brokers, who handle $70 \%$ of motor insurance premiums, use scoring-models which incorporate a fair number of client parameters to decide which insurance company is offering the best rate. If, generally speaking, distribution through brokers offers the client the best guarantee of competitive rates, it nonetheless inhibits product innovation. New services inevitably push premiums up, and, because of this, any innovative policy tends to be rejected by the broker's data-processing system even though the client is willing to pay a higher price for an additional service. Broker distribution also involves massive investment in data transmission and processing equipment in order to ensure that the client has effective real-time access to all offers available on the market.

This aspect of the broking process where the client is offered a premium rate increasingly close to the exact equivalent of his probable risk is no more than another form of market skimming, since clearly only those with the lowest potential exposure would stand to benefit from this particular mode of distribution. Companies are therefore obliged to invest in ever-increasing market segmentation in order to meet brokers' demands. 


\subsection{Personal IARD products are increasingly short-term ones and their short-term manage- ment is a threat to all concerned}

The main features of these Personal IARD products are that they are short-term, easily cancelled and attract an extremely price-sensitive clientele. A survey of customer price criteria, made in 1990 by Delphi and Andersen Consulting, shows that in practice price and quality of service (including promptness of settlement) take precedence both over the financial soundness of the company selected and over loyalty to a given distributer, be he general agent or broker.

Since price is the chief and most sensitive selection criterion for motor insurance, it is inevitable that customer instability is higher here than for other kinds of insurance. In Great Britain, where distribution is mainly handled by brokers, the annual customer turn-over rate is $30 \%$, while in France, where general agents handle a substantial share of business, this rate does not exceed from $10 \%$ to $15 \%$ due to the more personalized relationship between client and intermediary.

Everywhere in Europe, the quickening pace of the changes affecting rates is tending to push customer acquisition costs up because of the management and distribution surcharges involved. As a result, the average premium level tends to rise and with it company performance to deteriorate. The cost of this zapping is therefore having an adverse effect on the trend towards a market economy in motor insurance.

Initially, at least, while price criteria predominate, it is probable that the market will continue to segment. In the longer term, however, with the double erosion both of quality of service and company performance in this market, the tide of segmentation will begin to turn, revealing the adverse effects of this system and the extent to which it has become a burden on both parties. Did we not learn recently that the Prudential has decided to abandon the practice of using independent brokers for the sale of Non-Life insurance?

The prevailing trend towards a "maritime" model may therefore be expected to give ground to an "alpine" model more favourable to tied networks.

\section{Personal life assurance}

\subsection{The savings-management component in personal life assurance continues to grow}

Personal Life assurance has over time developed an increasingly heterogeneous range of products designed to meet a series of clearly differentiated household expectations. This development accords with the theory of the life-cycle. Young householders with limited savings capacity find themselves in need of some kind of security which, in exchange for reasonable contributions, will provide a steady income to their family in the event of their disability or decease. Householders in their maturity, concerned at the prospect of retirement, see insurance as a means of adding a steady supplement to their income. And finally, elderly householders are primarily concerned to pass on their estate to their heirs with minimum payment of death duties.

This development, which has been particularly clear in France, can also be seen in other European countries, although the existence of enterprise-managed pension funds, especially in Germany, the United Kingdom and the Netherlands, has tended to limit the number of personal pension plans. 
Indeed, the market-share of each of these types of Life Assurance product varies enormously from country to country. If capital bonds still constitute a substantial, albeit diminishing, share of Life Assurance in France, they are, by contrast, prohibited in Germany, since deemed to be too close to banking products and as such must be issued by financial establishments.

In Europe today, more than three fourths of personal Life premiums pertain to capital insurances of the endowment assurance type. Indeed, such endowment assurance frequently replaces pension policies because of its high average term and the annuity options available on maturity. The number of pension policies as such is still very limited owing to a lack of tax provisions specific to this kind of policy in most European countries.

\subsection{A market where the broker is almost entirely absent fails to live up to expectations}

The FSA or Financial Services Act, adopted in the United Kingdom in 1988 and designed to facilitate customer access to full information on the status of intermediaries and, more particularly, on the extent to which they are independent of companies, failed to live up to expectations.

This was due to the fact that, under the terms of the FSA, an independent intermediary is responsible for providing his client with the best possible advice regarding the latter's needs and for finding for his client the lowest available price on the market. He is bound, in addition, to inform his client as to the amount of the fee he will receive for the policy he proposes. Following some very stringent jurisprudence on a number of cases brought before the courts, brokers and other financial advisers, in order to be able to provide the best possible advice in question, were obliged at very great cost to invest in state-of-the-art data-processing equipment. Because brokers and advisers are obliged to be in constant touch with developments across the entire spectrum of the market, management became increasingly difficult and, more important, performance began to suffer to the point where, between 1988 and 1990 , more than one half of their number were forced to quit.

This contraction, however, was not due to mergers or take-overs between brokers but rather to bankruptcies, leading to every conceivable problem with the management of policies which either had to be transferred to other brokers still operating on the market or referred back to the companies that had originally issued them.

Not only, therefore, was the impact of this Act extremely adverse, but it came as a surprise to its advocates whose purpose had been to bring some order to broker-company relations and to increase the transparency of the fee system. Attempts to improve the situation, then, proved almost its undoing.

It would appear in fact that broking is destined to play a more minor role in Life assurance than in Non-Life, and that any attempt to bring too much rationalisation to distribution modes only tends to weaken them. The governments of other Community countries as well as the Brussels institutions themselves will doubtless be mindful of this in exercising their respective regulatory powers.

\subsection{As with all long-term products, brand image and policy cannot be ignored}

Obviously, a client is bound to be more concerned about the soundness of the company to which he entrusts his long-term savings than about that of an IARD (Fire, Accident, Liability and Transport) company whose role, in the client's eyes, is confined to discharging 
a legal, contractual or practical obligation in respect of third-party motor or home insurancc. Distribution through tied networks, the only way of ensuring a consistent brand policy, so crucial to this typc of insurance, would appear therefore to have a promising future, especially since broker distribution, as we have scen, is facing serious problems precisely in the country where it has devcloped most.

France is a special case. For several years now, distribution networks, quite unlike those traditionally associated with insurance, have been developing there. They are savings management associations, like the AFER or French Association for Pension-related Savings, offering their "clients" (or more properly their members) a centralized distribution system which, in addition to achicving cconomics in distribution costs, makes it possible to put pressure on companics to reduce their margins to a minimum. They are thus able to offer a higher ratc of return than is possible with traditional forms of distribution.

The success of such associations has forced companies to react by setting up in-house distributers to serve these associations, with the monnies collectcd being managcd by special so-called "area" funds.

Another peculiarity of the French scene has been the sudden entry into the Life assurance market during the 80 's by banks using subsidiary companies. Although this trend is now slowing, the recently established and rapidly expanding Life assurance companies are gluttons for own funds and the banks that own them, while welcoming stable resources of the kind these companies can supply, sometimes have problems in keeping to the Cooke ratios imposed upon them.

It is nevertheless a fact that in France, according to a recent Salomon Bros survey, banks have already acquired $39 \%$ of the "life" market. Nor indeed is France the only European country where banks have established subsidiaries through which to market Life products. To mention but two examples, the Monte dei Peschi di Sienna, the oldest Italian bank, and the Deutsche Bank have moved into this new area of business with considerable success.

Other banks have preferred to go into partnership with insurers making available to the latter their frequently highly complex distribution networks and thus increasing their cost-effectiveness. This is the idea behind Bankinsurance. The authors of the survey just mentioned, however, express doubts as to what can bc cxpected of a scheme of this kind in practice because of its failure to integrate entirely organisations, systems and products.

Some insurers, notably AGF and AXA, have pursucd the opposite strategem, as part of the global asset-managcment servicc they offer clients, by using their own distribution networks for the sale of bank products. In this way, Assurfinancc combines the professionalism of the insurer's tied networks and the company's brand image into a broad-bascd customer service covering all financial domains.

\section{Conclusions}

The foregoing study is not intended to be exhaustivc cither from the standpoint of the various classes of risk likely to be covered (transport and the so-called special risks such as surctyship and space risk, etc.) or from that of existing modes of distribution (postal sales, insurance sales-points in supermarkets, etc.).

As regards the first topic, the reason for this is that the risk premia concerned account for only a tiny part of the insurance market as a wholc and the policics covering such risks 
- which differ widely in terms of their technical content and of the size of the capital involved - more often than not relate to rather unusual forms of underwriting (specialized companies, pools, etc.).

As regards the second topic - distribution channels -, one is bound to admit that, although they have achieved some success, postal sales in the insurance sector are still far from the levels of market penetration they have achieved in other sectors of the economy. As to insurance sales-points in supermarkets, experiments to date appear to be far from conclusive. Indeed, having participated in one such experiment, the owner of a large supermarket chain recently concluded that, rather than go in for insurance, it would be more profitable to set up a delicatessen counter selling ready-to-eat dishes of bacon and beans...

The rather unorthodox nature of insurance, with its wide diversity of distributive channels, we noted at the outset, may thus be found to correspond to the very diversity of our trade. To sum up, we can distinguish three different types of cases: commercial risk (Life and Non-Life), unquestionably the preserve of the broker; Personal Non-Life and ordinary risks, destined in all probability to remain the main prerogative of the tied networks (general agents and salaried intermediaries); and Personal Life assurance, destined for the most part to remain the domain of the brand-name networks (insurance companies and banks). 